Journal of Computer Science 7 (10): 1474-1477, 2011

ISSN 1549-3636

(C) 2011 Science Publications

\title{
A Reduced Finite Element Model for Analyzing the Transverse Shear Stiffness of Truss-Like Core Sandwich Beam
}

\author{
${ }^{1}$ Suphattharachai Chomphan and ${ }^{2}$ Manit Leekitwattana \\ ${ }^{1}$ Department of Electrical Engineering, Faculty of Engineering at Si Racha, \\ ${ }^{2}$ Department of Naval Architecture and Marine Engineering, \\ International Maritime College, \\ Kasetsart University, 199 M.6, Tungsukhla, Si Racha, Chonburi, 20230, Thailand
}

\begin{abstract}
Problem statement: In structural analysis using finite element software, a number of finite element equations affect the speed of calculation time. A reduced finite element model should be used for analyzing structural responses to reduce the calculation time. Approach: This study presents the analysis of transverse shear stiffness of truss-like core sandwich beam using the reduced finite element model based on a unit cell approach. Two kinds of core topologies; an X-truss core and a bi-directional $\mathrm{X}$-truss core, were chosen to be analyzed. The presented reduced finite element model based on the unit cell approach was compared in transverse shear stiffness with the conventional three-point loaded beam approach. Results: Results showed that the unit cell approach could be used for analyzing the transverse shear stiffness of truss-like core sandwich beam with a good correlative with the conventional three-point loaded beam approach and a significantly reduced number of finite element equations. Conclusion: The transverse shear stiffness of truss-like core sandwich beam can be obtained from the reduced finite element model based on unit cell approach. This reduced finite element model can be used to reduce the number of finite element equations; consequently, the speed of calculation time is increased.
\end{abstract}

Key words: Finite element analysis, sandwich beam, unit cell, transverse shear stiffness, cell approach, calculation time, finite element equations, factorized transverse, accurate method

\section{INTRODUCTION}

In recent structural engineering analysis, a finite element method is a tool for analyzing structural responses, e.g., stiffness of beam structures. This method can be used in corporation with the force and distortion relationship of three-point loaded beam and of unit cell approaches.

The force and distortion relationship of three-point loaded beam approach is an accurate method for analyzing the transverse shear stiffness of sandwich beams (Leekitwattana et al., 2011; Libove and Hubka, 1951). It is, however, an expensive time-consuming method because of the need of repetitive beam tests. In finite element analysis, the repetitive beam tests lead to an expensive calculation time because of a large number of finite element equations.

The force and distortion relationship of unit cell approach is another analytical method for analyzing the transverse shear stiffness of sandwich beams. Libove and Hubka (1951) have used this method in analytical study of simple corrugated core sandwich beams. Lok and Cheng (2000) have also used it for analyzing the transverse shear stiffness of simple truss core sandwich beams. It was found that the force and distortion relationship of unit cell approach is also an accurate method if applied for the simple truss-like core sandwich beam (Libove and Hubka, 1951; Lok and Cheng, 2000)

This study aims to present an application of the force and distortion relationship of unit cell approach in finite element analysis of complex truss-like core sandwich beams and to outline the advantage of this approach in comparison with the force and distortion relationship of three-point loaded beam approach.

\section{MATERIALS AND METHODS}

Three-point loaded beam approach: In practice, the transverse shear stiffness of beams can be deduced from the relationship between the applied vertical load, $P$ and the corresponded vertical deflection at midspan, $\Delta_{\mathrm{z}}$, of a series of three-point loaded beam tests (Nordstrand and Carlsson, 1997; Zangani et al., 2007) as demonstrated in Fig. 1.

Corresponding Author: Suphattharachai Chomphan, Department of Electrical Engineering, Faculty of Engineering at Si Rach, Kasetsart University, 199 M.6, Tungsukhla, Si Racha, Chonburi, 20230, Thailand 


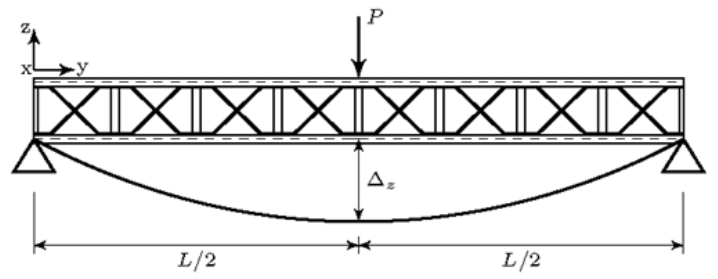

(a)

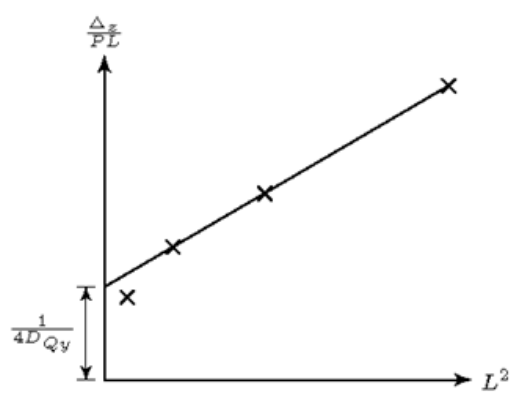

(b)

Fig. 1: A method for analyzing the transverse shear stiffness from the force and distortion relationship of three-point loaded beams

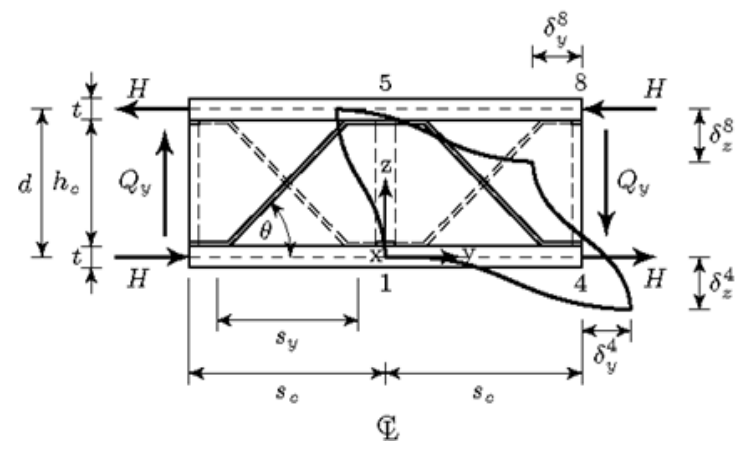

Fig. 2: A method for analyzing the transverse shear stiffness from the force and distortion relationship of unit cell (Leekitwattana et al., 2011)

The relationship between the applied force, $\mathrm{P}$ and the corresponded deflection, $\Delta_{\mathrm{z}}$, can be expressed as Eq. 1. This expression provides the basis for determination of the transverse shear stiffness, $\mathrm{D}_{\mathrm{Qy}}$, from plotting $\Delta_{\mathrm{z}} / \mathrm{PL}$ and where $\mathrm{L}$ is the length of the beam, from a series of required data $\mathrm{P}, \Delta_{\mathrm{z}}$, and $\mathrm{L}$ in which $\mathrm{D}_{\mathrm{Qy}}$ can be yielded from the approximate interception point on the $\Delta_{\mathrm{Z}} / \mathrm{PL}$ axis (Nordstrand and Carlsson, 1997; Souiyah et al., 2009; Urgessa, 2009; Thomas and Dozier, 2010; Mohsen, 2010; Rahman et al., 2009):

$$
\mathrm{D}_{\mathrm{Qy}}=\frac{\mathrm{Q}_{\mathrm{y}}}{\frac{\delta_{\mathrm{y}}^{4}+\delta_{\mathrm{y}}^{8}}{\mathrm{~d}}+\frac{\delta_{\mathrm{z}}^{4}}{\mathrm{~s}_{\mathrm{c}}}}
$$

Unit cell approach: In practice, the transverse shear stiffness of beams can also be deduced from the relationship between the applied transverse shear force, $\mathrm{Q}_{\mathrm{y}}$ and the corresponded deflections $\Delta_{\mathrm{y}}$ and $\Delta_{\mathrm{z}}$ of a unit cell which is a repetitive unit of a sandwich beam (Leekitwattana et al., 2011), as demonstrated in Fig. 2.

The relationship between the applied transverse shear force Qy and the corresponded deflections $\Delta \mathrm{z}$ and can be expressed as Eq. 2. This expression provides the direct calculation of the transverse shear stiffness, DQy:

$$
\mathrm{D}_{\mathrm{Qy}}=\frac{\mathrm{Qy}}{\frac{\delta_{\mathrm{y}}^{4}+\delta_{\mathrm{y}}^{8}}{\mathrm{~d}}+\frac{\delta_{\mathrm{z}}^{4}}{\mathrm{~s}_{\mathrm{c}}}}
$$

Finite element software: The commercial finite element software ANSYS Release 11 is used in this study. The ANSYS is run under the operating software MS Windows XP Professional Version 2002. The hardware condition is a desktop computer with Intel ${ }^{\circledR}$ Core $^{\mathrm{TM}} 2$ CPU 6600 @ 2.40 $\mathrm{GHz}$ and $1.98 \mathrm{~GB}$ of RAM.

Finite element models: Three-dimensional finite element models of truss-like core sandwich beam and of its repetitive unit cell, as shown in Fig. 3, are analyzed. The sandwich beam consists of the top and bottom steel faceplates and a series of truss-like core. These parts are modeled using the SOLID45 element type-an eight-node element having three degrees of freedom in nodal translations at each node. In this study, the typical $2 \mathrm{~mm}$ finite element mesh size is used. The connections between the faceplates and core elements are defined as fully rigid.

The sandwich beam, as shown in Fig. 3a, has simply supports at the lines 1-1' and 2-2'. An additional constraint boundary condition is set up along the lines 3-3' and 4-4' to reduce the local deformation effect beneath the loading line 5-5' which is subjected to a unit transverse force per unit width of the sandwich beam (Table 1).

The repetitive unit cell, as shown in Fig. 3b, has a fixed support at line 1-1' and a roller support at line 5-5'. Additional constraint boundary conditions are also set up along the lines 4-4' and 8-8' to maintain the displacement equality of both lines in the $\mathrm{z}$-direction.

In this study, the truss-like cores are $\mathrm{X}$-truss core and bi-directional corrugated-strip core, as shown in Fig. 4. 


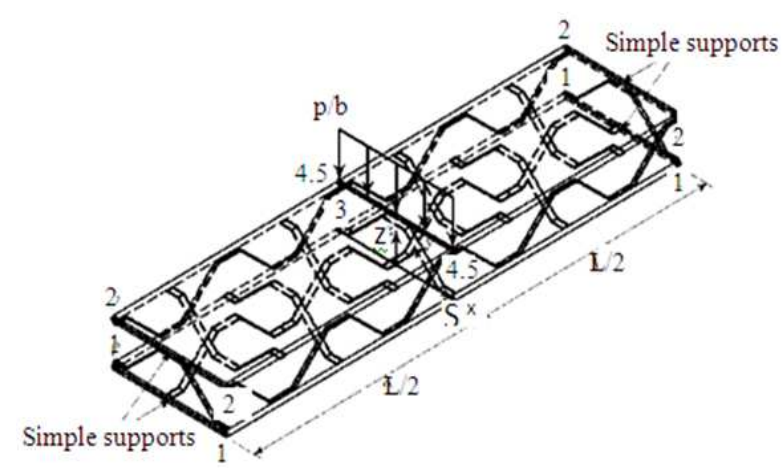

(a)

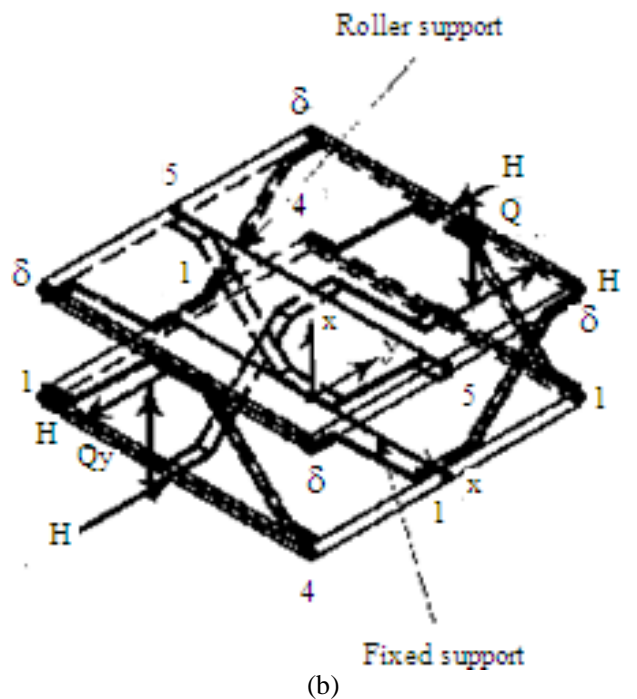

Fig. 3: A finite element model of (a) three-point loaded sandwich beam and of (b) its repetitive unit cell

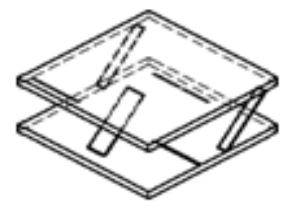

(a)

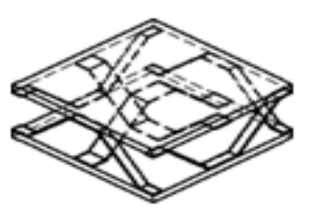

(b)

Fig. 2: A model of (a) X-truss core and (b) bi-irectional corrugated-strip core
Table 1: Configuration of sandwich beams

\begin{tabular}{lll}
\hline Dimensions & Value & Unit \\
\hline Width of sandwich beam, b & 100 & $\mathrm{~mm}$ \\
Thickness of sandwich faceplate, $\mathrm{t}$ & 12 & $\mathrm{~mm}$ \\
Depth of sandwich core,hc & 120 & $\mathrm{~mm}$ \\
Width of core plate, bc & 25 & $\mathrm{~mm}$ \\
Thickness of core plate,tc & 2 & $\mathrm{~mm}$ \\
Length of flat leg of core plate,fc & 20 & $\mathrm{~mm}$ \\
\hline
\end{tabular}

Table 2: Physical properties of steel

\begin{tabular}{lll}
\hline Properties & Value & Unit \\
\hline Yield Stress, $\mathrm{f}_{\mathrm{y}}$ & 355000 & $\mathrm{~N} \mathrm{~mm}_{\square}$ \\
Modulus of ElasticityEs, & 206,000 & $\mathrm{~N} \mathrm{~mm}_{\square}$ \\
Poisson's Ratio, $\mathrm{v}_{\mathrm{s}}$ & 0.30000 & \\
\hline
\end{tabular}

Material properties of steel: In this finite element study, the steel with perfectly elastic-plastic property is used. In the ANSYS, this material property of steel is defined using the bi-linear model. The tension and compression behaviors of steel are assumed the same. The physical properties of steel are defined in Table 2.

\section{RESULTS}

Based on the transverse shear stiffness formulation techniques presented in the materials and methods section, the transverse shear stiffness, $\mathrm{D}_{\mathrm{Qy}}$, of the sandwich beam with two core topologies, i.e., the X-truss core topology and the bi-directional corrugated-strip core topology, are obtained and presented in Figs. 5-6.

In both Fig. the transverse shear stiffness, $\mathrm{D}_{\mathrm{Qy}} / \mathrm{E}_{\mathrm{b}}$ $t_{b}$, is first factorized by $E_{s} t$ where $E_{S}$ is the modulus of elasticity of steel and is the thickness of sandwich faceplate. Then, it is plotted against $s_{y} / d$ in the range of $0.25 \leq \mathrm{s}_{\mathrm{y}} / \mathrm{d} \leq$ where $\mathrm{s}_{\mathrm{y}}$ is the horizontal projection of the extended local neutral axis of the inclined part of the core (Fig. 2) and is the effective depth of the sandwich beam, i.e., $\mathrm{d}=\mathrm{t}$. Here, $\mathrm{s}_{\mathrm{y}} / \mathrm{d}$ is used to define the angle of the inclined part of the core. It is equal to $\left(\mathrm{s}_{\mathrm{c}}-2 \mathrm{f}_{\mathrm{c}}\right) /\left(\mathrm{h}_{\mathrm{c}-\text {. }}\right.$ Thus, the horizontal length of the unit cell, $\mathrm{s}_{\mathrm{c}}$, can be obtained from this expression.

Table 3-4 present the approximate numbers of finite element equations needed to solve in the analysis module of the ANSYS obtained from the three-point loaded X-truss core sandwich beams and from the three-point loaded bi-directional corrugated-strip core sandwich beams, respectively.

\section{DISCUSSION}

From the comparison of the factorized transverse shear stiffness, $\mathrm{D}_{\mathrm{Qy}} / \mathrm{E}_{\mathrm{b}} \mathrm{t}_{\mathrm{b}}$, of the X-truss core sandwich beams obtained from the Three-point Loaded Beam approach (TPB) and the Unit Cell approach (UC) as presented in Fig. 5, it can be seen that the unit cell approach agrees very well with the three-point loaded beam

approach. 
Table 3: Approximate numbers of finite element equations needed to solve in the analysis module of the ANSYS obtained from the three-point loaded X-truss core sandwich beams

Number of unit cells in the sandwich beams

\begin{tabular}{|c|c|c|c|c|c|c|c|c|c|}
\hline $\mathrm{s}_{\mathrm{r}} /$ & 1 & 2 & 3 & 4 & 5 & 6 & 7 & 8 & 9 \\
\hline 0.50 & 132,167 & 264,3340 & 396,50100 & 528,66800 & 660,835 & 793,002 & 925,169 & $1,057,336$ & $1,189,503$ \\
\hline 1.00 & 201,887 & 403,7740 & 605,66100 & 807,54800 & $1,009,435$ & $1,211,322$ & $1,413,209$ & $1,615,096$ & N/A \\
\hline 1.50 & 271,607 & 543,2140 & 814,82100 & $1,086,428$ & $1,358,035$ & $1,629,642$ & N/A & N/A & N/A \\
\hline 43,214 & 814,821 & $1,086,428$ & $1,358,035$ & $1,629,642$ & N/A & N/A & N/A & & \\
\hline
\end{tabular}

Table 4: Approximate numbers of finite element equations needed to solve in the analysis module of the ANSYS obtained from the three-point loaded X-truss core sandwich beams

Number of unit cells in the sandwich beams

\begin{tabular}{llllllllll}
\hline $\mathrm{s}_{\mathrm{r}} /$ & 1 & 2 & 3 & 4 & 5 & 6 & 7 & 8 \\
\hline 0.50 & 132,167 & 264,334 & 396,501 & 528,668 & 660,835 & 793,002 & 925,169 & $1,057,336$ & $1,189,503$ \\
1.00 & 201,887 & 403,774 & 605,661 & 807,548 & $1,009,435$ & $1,211,322$ & $1,413,209$ & $1,615,096$ & N/A \\
1.50 & 271,607 & 543,214 & 814,821 & $1,086,428$ & $1,358,035$ & $1,629,642$ & N/A & N/A & N/A \\
43,214 & 814,821 & $1,086,428$ & $1,358,035$ & $1,629,642$ & N/A & N/A & N/A & &
\end{tabular}

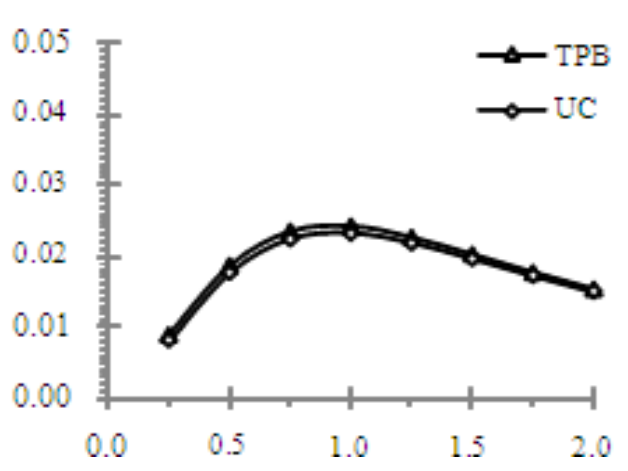

Fig. 3: Factorized transverse shear stiffness, t, of $\mathrm{X}$ truss core sandwich beams obtained at any ratio from the three-point loaded beam approach (TPB) and the unit cell approach (UC)

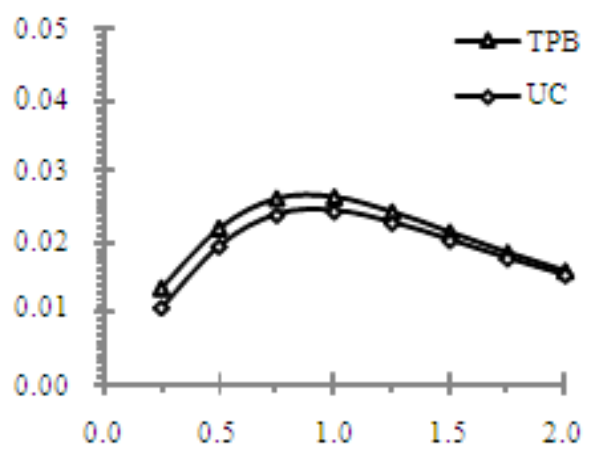

Fig. 4: Factorized transverse shear stiffness, t, of bidirectional corrugated-strip core sandwich beams obtained at any ratio from the Three-Point loaded Beam approach (TPB) and the Unit Cell approach (UC)
From the comparison of the factorized transverse shear stiffness, $\mathrm{D}_{\mathrm{Qy}} / \mathrm{E}_{\mathrm{b}} \mathrm{t}_{\mathrm{b}}$, of the bi-directional corrugated-strip core sandwich beams obtained from the Three-Point Loaded ssBeam approach (TPB) and the Unit Cell approach (UC) as presented in Fig. 6, it can also be seen that the unit cell approach agrees very well with the three-point loaded beam approach with a few percentage differences.

According to these comparisons, it can be seen that the transverse shear stiffness, $\mathrm{D}_{\mathrm{Qy}}$, of the complex trusslike core sandwich beams obtained from the unit cell approach-a reduced finite element model-is well consistent with the contemporary three-point loaded beam approach. Therefore, it is reasonable to conclude that the reduced finite element model based on the unit cell approach is accurate enough. It can be used for analyzing the transverse shear stiffness, $p$, of not only the simple truss core sandwich beams but also the complex truss-like core sandwich beams, i.e., the Xtruss core and the bi-directional corrugated-strip core sandwich beams presented in this study.

The unit cell approach is considerably more advantageous than the three-point loaded beam approach when applied to the finite element method. This is because the number of finite element equations of the unit cell model is less than the number of finite element equations of the three-point loaded beam model.

It can be seen from Table 3-4 that the numbers of finite element equations obtained from the three-point loaded beams are approximately six times more than those obtained from the single unit cell. In addition, the unit cell approach can provide the direct calculation of the transverse shear stiffness, $\mathrm{D}_{\mathrm{Qy}}$, in a 
single finite element analysis whereas the three-point loaded beam approach needs a series of repetitive finite element analysis which may be greater than six times in this study.

\section{CONCLUSION}

This study presents the application of the force and distortion relationship of unit cell approach to obtain the transverse shear stiffness, $\mathrm{D}_{\mathrm{Qy}}$, of the complex trusslike core sandwich beams in finite element analysis. Two core topologies of the X-truss core and the bidirectional corrugated-strip core are presented as examples of complex truss-like core topology. The responses of the transverse shear stiffness, $D_{\mathrm{Qy}}$, obtained from the unit cell approach are presented and compared with those obtained from the three-point loaded beam approach. It is found that the unit cell approach agrees very well with the three-point loaded beam approach. The unit cell approach can be applied to a finite element analysis to reduce the number of finite element equations; consequently, it can be used to increase the speed of calculation time.

\section{REFERENCES}

Leekitwattana, M., S.W. Boyd and R.A. Shenoi, 2011. Evaluation of the transverse shear stiffness of a steel bi-directional corrugated-strip-core sandwich beam. J. Constr. Steel Res., 67: 248-254. DOI: 10.1016/J.JCSR.2010.07.010

Libove, C. and R.E. Hubka, 1951. Elastic Constants for Corrugated-Core Sandwich Plate. Internet Archive.
Lok, T.S. and Q.H. Cheng, 2000. Elastic stiffness properties and behavior of truss-core sandwich panel. J. Struct. Eng., 126: 552-560. DOI: 10.1061/(ASCE)0733-9445(2000)126:5(552)

Mohsen, Q., 2010. Factors affecting the synthesis and formation of single-phase barium hexaferrite by a technique of oxalate precursor. Am. J. Applied Sci., $\quad 7$ : 914-921. 10.3844/ajassp.2010.914.921.

Nordstrand, T.M. and L.A. Carlsson, 1997. Evaluation of transverse shear stiffness of structural core sandwich plates. Compos. Struct., 37: 145-153. DOI: 10.1016/S0263-8223(97)80007-4

Rahman, M. M., A. B. Rosli, M.M. Noor, M.S.M. Sani and J.M. Julie, 2009. Effects of spot diameter and sheets thickness on fatigue life of spot welded structure based on FEA Approach. Am. J. Applied Sci., 6: 137-142. 10.3844/ajassp.2009.137.142.

Souiyah, M., A. Muchtar, A. Alshoaibi and A.K. Ariffin, 2009. Finite element analysis of the crack propagation for solid materials. Am. J. Applied Sci., 6: 1396-1402. DOI: 10.3844/ajassp.2009.1396.1402.

Thomas, M. B. and L. Dozier, 2010. Finite element modeling of transient temperatures in a smallcaliber projectile. Am. J. Eng. Applied Sci., 3: 355362. DOI: 10.3844/ajeassp.2010.355.362.

Urgessa, G.S., 2009. Finite element analysis of composite hardened walls subjected to blast loads. American J. Eng. Applied Sci., 2: 804-811. DOI: 10.3844/ajeassp.2009.804.811.

Zangani, D., M. Robinson and A.G. Gibson, 2007. Evaluation of stiffness terms for z-cored sandwich panels. Applied Compos. Mater., 14: 159-175. DOI: 10.1007/s10443-007-9038-y 